Chapter 15

\title{
Simian Malaria Parasites: Special Emphasis on Plasmodium knowlesi and Their Anopheles Vectors in Southeast Asia
}

\author{
Indra Vythilingam and Jeffery Hii \\ Additional information is available at the end of the chapter
}

http://dx.doi.org/10.5772/54491

\section{Introduction}

Simian malaria parasites were first reported in Malayan monkeys by Daniels in 1908 [1]. It had been assumed for a long time that transmission of simian malaria to humans would not be possible. However, an accidental infection of scientists in Atlanta, USA by mosquito bites in the laboratory proved that a simian malaria species- Plasmodium cynomolgi can be transmitted to humans [2, 3]. In 1965 the first natural infection in human was reported in an American surveyor who was infected in the jungles of Pahang, Malaysia [4]. Fortunately he returned to USA and was detected first as Plasmodium falciparum and later revised to Plasmodium malariae due to the band form of the parasite. Further examination proved that it was actually Plasmodium knowlesi [4].

Plasmodium knowlesi was first found in Macaca fascicularis monkeys that were brought to India from Singapore. Drs Knowles and Das Gupta knew that they were dealing with a new malaria parasite but did not provide a binomial nomenclature. It was Sinton and Muligan who formally named the new species as P. knowlesi [5] after Dr. Knowles. Studies that were carried out before the first human case was reported unveiled many new simian malaria parasites but no human cases. After the first human case was reported in 1965, blood samples were collected from about 1000 people from surrounding villages in West Malaysia where the case of $P$. knowlesi was found but none were positive for simian malaria [6]. However, a presumptive case was reported from Johore, a southern state in peninsular Malaysia [7].

Mosquito surveys carried out in the area where the first case occurred did not reveal any sporozoite infections in the mosquitoes. However, studies in the coastal areas of Selangor in peninsular Malaysia found Anopheles hackeri to be a vector of $P$. knowlesi [8] and this mosquito 
was attracted only to non-human primates and would not come to bite humans. Thus, at that time it was concluded that simian malaria parasites would not easily affect humans and if it did human malaria cases would occur at very low levels [9]. In 2004 a large focus of knowlesi malaria among humans in Sarawak, Malaysian Borneo was reported [10]. This significant finding stimulated many scientists who were interested in the field of simian malaria in humans and their vectors and hosts. Southeast Asia has now become a focal point for the distribution of $P$. knowlesi in humans. This chapter will describe the simian malaria parasites in non-human primates, the bionomics of vectors involved in transmission, human cases of knowlesi malaria and the challenges in relation to elimination of malaria.

\section{Simian malaria parasites and their hosts}

In Southeast Asia, there are 13 species of Plasmodium affecting non-human primates [11]. Of these Plasmodium coatneyi, P. cynomolgi, P. fieldi, P. fragile, P. inui, P. knowlesi and P. simiovale are known to occur in macaques and leaf monkeys [12]. However, of the seven species, $P$. fragile has been reported in both India and Sri Lanka while $P$. simiovale is restricted only to Sri Lanka [12]. Plasmodium eylesi, P. jefferyi, P. youngi and P. hylobati are found in gibbons while P. pitheci and $P$. silvaticum are found in orangutans in Borneo. These malaria parasites are found throughout mainland Southeast Asia and associated islands within the Wallace's line [13].

Information is currently available on the non-human primate malaria especially in Malaysia. Thus, so far five species of simian malaria parasites in non-human primates (macaques) have been reported from Malaysia $[12,14]$. The simian malaria parasite $P$. cynomolgi is a species that had been experimentally transmitted to humans $[3,15]$. Plasmodium cynomolgi in monkeys has many of the characteristics seen during infection of humans with $P$. vivax [16]. It was always believed that monkey malaria was specific for monkeys and human malaria was specific for humans. However, in 1960 accidental infections in the laboratory of simian malaria to humans by mosquito bites led to investigative studies to be carried out in Malaysia and this resulted in the description of many new simian malaria parasites [17-20].

Simian malaria parasites have been detected in three main species of non-human primates. They are Macaca fascicularis, Macaca nemestrina and Presbytis melalophos [19, 20]. In the 1960's studies on malaria parasites of $M$. nemestrina revealed that this non-human primate can harbour the following simian malaria species: P. cynomolgi, P. inui, P. knowlesi and P. fieldi [19] Of these P. fieldi was a new species found in this macaque [17]. Currently, P. fieldi has been found as mixed infection in longtailed macaques but less frequently compared to the other simian malaria parasites [14]. Only $4 \%$ of the macaques had P.fieldi mono-infection in a study in Sarawak, Malaysian Borneo [14]. In Malaysian Borneo the predominant species found in the longtailed macaques was P. inui (82\%) followed by P. knowlesi (78\%), P. coatneyi (66\%) and P. cynomolgi (56\%) [14]. However, in Singapore P. knowlesi was the predominant species among long-tailed macaques (68.2\%), followed by P. cynomolgi (66.6\%), P. fieldi (16.7\%), P. coatneyi (3\%) and P. inui (1.5\%) [21]. In Selangor, out of the 107 samples of macaque blood tested for malaria, $64.5 \%$ were positive for Plasmodium of which $23.3 \%$ were positive for $P$. knowlesi [22]. 
Plasmodium coatneyi was successfully established when sporozoites from An. hacker collected from Rantau Panjang Selangor, were inoculated into an uninfected rhesus monkey. The monkey exhibited infection after a prepatent period of 14 days. The young trophozoites were not easily distinguishable from those of $P$. falciparum and demonstrated a tertian cycle thus leading to a new species [23]. This is the first instance of finding a new species of malaria in the vector before it was known from the primate host. Subsequently P. coatneyi was also isolated from M. fascicularis from the same area and also from the Philippines [24].

The pig-tailed macaque - Macaca nemestrina occurs in various sub-species from easternmost India and Bangladesh, through Myanmar and Thailand, Malaysia, Sumatra and Kalimantan [19]. This animal is trained to harvest coconuts from tall trees and is kept as a pet by their owners. They coexist with long-tailed macaques-M. fascicularis but are ecologically less diverse in their choice of habitats [19].They are also less commonly seen compared to M. fascicularis. The parasites found in the pig-tailed macaques were P. cynomolgi, P. inui, P. knowlesi, P. fieldi and Hepatocystis [19].

\section{History of natural infection of $P$. knowlesi in human host}

Scientists have always been curious as to the possibility of humans being infected with nonhuman primate malaria. This interest was intensified when two scientists working in the Memphis laboratory were infected with $P$. cynomolgi. They were conducting infection studies in the laboratory and they were dissecting a large number of mosquitoes heavily infected with malaria parasites two weeks prior to coming down with the illness [2]. Following these infections, scientists decided to survey areas in peninsular Malaysia and search for natural transmission of simian malaria in humans. There were also attempts by scientists to probe into the natural transmission of monkey malaria to humans in the northernmost state of peninsular Malaysia [25]. In the first survey they did not come across any human cases but described new species of monkey malaria parasites in macaques [6].

In 1965, an American surveyor working in Bukit Kertau in Pahang, Malaysia came down with malaria. Fortunately he returned to USA where he was diagnosed as P. knowlesi [4]. This was the first natural infection reported in humans. The surveyor was apparently working in the forested area at night. American scientists along with the scientists from the Institute for Medical Research carried out extensive surveys in that area where the surveyor was infected. Blood from 1117 persons from 17 villages were examined for malaria parasites by microscopy using Giemsa stained slides. Blood was also inoculated into rhesus monkeys to determine if there were natural infections of simian malaria in humans. Of these only 28 had malaria infection, 11 were P. falciparum, 13 P.vivax and four were not identifiable. None of the rhesus monkeys developed malaria parasites [6]. Thus it was concluded that simian malaria would not easily infect humans. In 1970's a presumptive case of $P$. knowlesi was reported from Johore, peninsular Malaysia [7]. 


\section{Cases of knowlesi malaria in Southeast Asia}

In 2004, a large focus of human knowlesi malaria cases were reported from Sarawak, Malaysian Borneo [10]. In that study it was found that $58 \%$ of the patients, admitted at the Sarawak hospital, were found to be infected with knowlesi malaria using molecular tools. These were misidentified by microscopy as $P$. malariae. Early trophozoites of $P$. knowlesi in the erythrocyte resemble that of $P$. falciparum such as double chromatin dots, multiple-infected erythrocytes and appliqué forms [26]. Besides the late and mature trophozoites, schizonts and gametocytes of $P$. knowlesi in human infections were generally indistinguishable from those of $P$. malariae. Moreover, 'band form' trophozoites, which are a characteristic feature for $P$. malariae parasites $[27,28]$ were observed in more than half of the blood films examined by Lee et al [26]. 'Sinton and Mulligan's stippling' in erythrocytes infected with $P$. knowlesi was noted previously in infections in rhesus monkeys [27] and humans [7]. However, in present knowlesi cases only faint stippling was evident in some of the infected erythrocytes with mature trophozoite and schizont stages $[10,26]$. Thus, human infections with $P$. knowlesi have been mistaken for $P$. falciparum malaria when the infecting parasites were predominantly at the early trophozoite or ring form developmental stage and as P. malariae when in the late trophozoite or band form. Figure 1 shows the different stages of development of $P$. knowlesi.
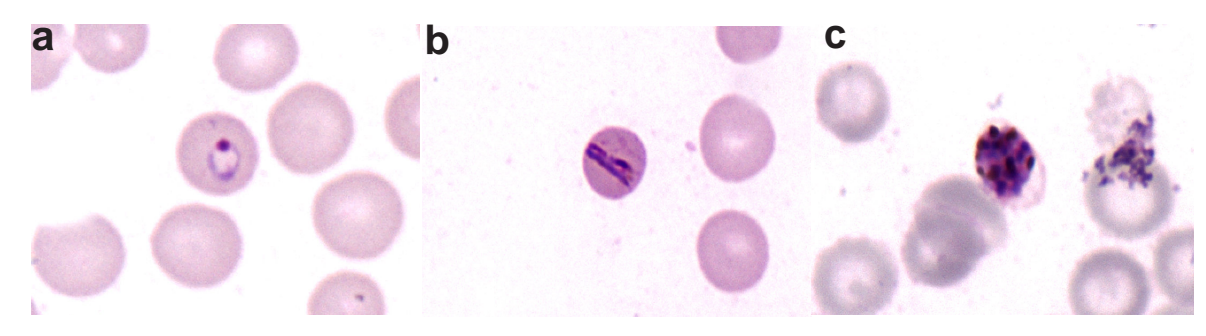

Figure 1. Giemsa stained thin blood film of $P$. knowlesi as seen with $100 \times$ objective. a). trophozoite b) band form of trophozoite, c) schizont

After the publication in 2004 [10], more cases were reported in Malaysia [29-32] and also from other countries in Southeast Asia with the exception of Lao PDR. To date cases have been reported from Thailand [33-35], Philippines [36],Vietnam [37], Indonesia [38], Cambodia [39], Myanmar [40] and Singapore [41]. Malaysia has reported the highest number of cases in the region. Plasmodium knowlesi is now considered as the fifth malaria parasite affecting humans [42] and is detected by molecular methods. However, some still believe that it is a simian malaria since human to human transmission has not been proven [13].

A study has shown that $M$. fascicularis experimentally infected with $P$. knowlesi erythrocytic parasites from humans developed pre patent infection on day seven and demonstrated diurnal sub-periodic pattern [43]. It is the only primate malaria with a 24-hour erythrocytic cycle [44] while $P$. falciparum has a 48 hour cycle and $P$. malariae a 72 hour cycle. 
Knowlesi malaria has shown to be life threatening and mortality has been reported [29, 31]. From December 2007 to November 2009 six (27\%) out of 22 patients with severe knowlesi malaria died in Sabah [31]. Cases of knowlesi malaria are also occurring in areas where human malaria cases have been reduced or in malaria free areas [45]. People can contract malaria either outside their houses in rural settings, in farms where they work or in the forest while hunting or working.

\section{Knowlesi malaria associated with travellers to Southeast Asia}

Naturally acquired cases of $P$. knowlesi have been reported from travellers visiting this region. A New Zealand pilot working in Sabah and Sarawak north of Bintulu Malaysian Borneo was diagnosed as $P$. knowlesi in New Zealand when he fell ill. The sequence of the parasite had a $100 \%$ homology to the Vietnam strain [46]. A lady born in the Philippines and residing in USA for more than 25 years came down with knowlesi malaria after visiting Palawan in the Philippines where she stayed in a log cabin close to the forest edge. She fell ill and on her return to USA was diagnosed as P. knowlesi [47]. A Finish traveller spent about 5 days in the jungle on the north-western coast of peninsular Malaysia and fell ill after he returned to Finland. He was diagnosed with P. knowlesi parasitaemia by PCR and sequencing showed $100 \%$ homology with P. knowlesi sequence from Malaysian Borneo and a Macaca mullata from Colombia [48]. A Swede who travelled to the Bario Highlands in Malaysian Borneo came down ill on his return to Sweden and was diagnosed as suffering from knowlesi malaria [49]. A Spanish traveller who spent six months travelling around Southeast Asia - in forested areas was diagnosed as knowlesi malaria when he returned to Spain [50]. A French tourist returning from Thailand was diagnosed as P. knowlesi [51]. This shows that the knowlesi malaria is currently a serious public health problem and not just single occasional episodes.

\section{Bionomics of simian malaria vectors and trapping techniques}

\subsection{Distribution}

The distribution of $P$. knowlesi in the natural monkey hosts and transmission to humans are restricted to mosquito vectors of the Anopheles Leucosphyrus Group confined to Southeast Asia [52]. It is currently recognized that under natural forest conditions, most if not all members of the Leucosphyrus Group apparently feed primarily on monkeys in the canopy, transmitting various plasmodia [53]. In Harbach's review [54], the Leucosphyrus Group in the Neomyzomyia Series contains 20 named species [55, 56], one unnamed species (aff. takasagoensis) and two geographical forms (Con Son form from island off South Vietnam and Negros form from Negros island in Philippines) [55] divided between the Hackeri, Leucosphyrus and Riparis Subgroups. According to Manguin et al. [57] and Sallum et al. [56], the Leucosphyrus Subgroup consists of the Dirus and Leucosphyrus complexes, which includes seven and five sibling species, respectively. Species belonging to the Leucosphyrus complex are also important 
vectors of human malaria and lymphatic filariasis and are distributed in the South and Southeast Asia regions. The current vectorial status and geographical distribution of the Leucosphyrus Group are listed in Table 1 and Figure 2.

\begin{tabular}{|c|c|c|c|c|}
\hline Complex & Vector species & $\begin{array}{c}\text { Species of } \\
\text { Plasmodium }\end{array}$ & $\begin{array}{l}\text { Vertebrate } \\
\text { hosts }\end{array}$ & Distribution \\
\hline \multirow[t]{5}{*}{ Leucosphyrus } & $\begin{array}{l}\text { An. leucosphyrus Donitz } \\
(h v)^{1}\end{array}$ & $P f, P V, P m^{2}$ & Human & Indonesia, Sumatra \\
\hline & $\begin{array}{l}\text { An. latens Sallum \& } \\
\text { Peyton (hv, sv, fv) }\end{array}$ & $\begin{array}{c}\text { Pf, Pv, Pm } \\
\text { P. inui [78] } \\
\text { P. knowlesi, P. inui, P. } \\
\text { coatneyi, P. fieldi }[79]\end{array}$ & $\begin{array}{c}\text { Human } \\
\text { M. fascicularis, } \\
\text { M. nemestrina } \\
\text { P. melalophos } \\
\text { [19-22] }\end{array}$ & $\begin{array}{c}\text { Indonesia, East Malaysia, } \\
\text { West Malaysia, } \\
\text { Thailand } \\
\text { Sarawak: } \\
\text { East Malaysia: Sarawak }[45,75] \\
\text { West Malaysia }[56]\end{array}$ \\
\hline & $\begin{array}{l}\text { An. introlatus Colless } \\
\text { (sv) }\end{array}$ & $\begin{array}{l}\text { P. cynomolgi, P. fieldi } \\
{[78]}\end{array}$ & $\begin{array}{c}\text { M. fascicularis, } \\
\text { M. nemestrina } \\
\text { P. melalophos } \\
\text { [19-22] }\end{array}$ & $\begin{array}{c}\text { Indonesia } \\
\text { West Malaysia, } \\
\text { Thailand [56] }\end{array}$ \\
\hline & $\begin{array}{c}\text { An. balabacensis Colless } \\
(\mathrm{hv}, \mathrm{sv}, \mathrm{fv})\end{array}$ & $\begin{array}{c}P \text {. knowlesi }[45] ; \\
\text { possibly } P \text {. coatneyi \& } P \text {. } \\
\text { inui }[73]\end{array}$ & $\begin{array}{c}\text { M. fascicularis } \\
{[73]}\end{array}$ & $\begin{array}{c}\text { Brunei, } \\
\text { Indonesia, } \\
\text { East Malaysia, } \\
\text { Philippines [56] }\end{array}$ \\
\hline & An. baisasi Colless & $\begin{array}{l}\text { Information } \\
\text { inadequate }\end{array}$ & & Luzon, Philippines \\
\hline \multirow[t]{3}{*}{ Dirus } & $\begin{array}{l}\text { An. dirus Peyton \& } \\
\text { Harrison (hv, sv fv) }\end{array}$ & P. knowlesi [76-77] & $\begin{array}{c}\text { Human } \\
\text { M. fascicularis, } \\
\text { [35] }\end{array}$ & $\begin{array}{l}\text { Cambodia, } \\
\text { China, Vietnam, } \\
\text { Laos, Thailand }\end{array}$ \\
\hline & $\begin{array}{l}\text { An. cracens Sallum \& } \\
\text { Peyton (hv, sv, fv) }\end{array}$ & $\begin{array}{c}\text { Probable vector of } \\
\text { human malaria }[56] \\
\text { P. knowlesi }[30,72] \\
\text { P. cynomolgi, P. inui } \\
{[80]}\end{array}$ & $\begin{array}{c}\text { M. fascicularis } \\
\text { [30] }\end{array}$ & $\begin{array}{l}\text { Indonesia, } \\
\text { West Malaysia, } \\
\text { Thailand }\end{array}$ \\
\hline & $\begin{array}{l}\text { An. baimaii Sallum \& } \\
\text { Peyton (hv, fv) }\end{array}$ & $\mathrm{Pf}, \mathrm{Pv} \mathrm{Pm}$ & Human & $\begin{array}{l}\text { Bangladesh, } \\
\text { India, Thailand, } \\
\text { Myanmar, China }\end{array}$ \\
\hline \multirow[t]{3}{*}{ Hackeri } & $\begin{array}{l}\text { An. mirans Sallum \& } \\
\text { Peyton (sv) }\end{array}$ & $\begin{array}{c}\text { P. cynomolgi, P. inui } \\
{[56]} \\
\text { P. inui shortii; P. fragile } \\
{[56]}\end{array}$ & & India, Sri Lanka \\
\hline & An. hackeri Edwards (sv) & $\begin{array}{c}\text { P. cynomolgi, P. inui, } P \text {. } \\
\text { fieldi, P. coatneyi, P. } \\
\text { knowlesi [52] }\end{array}$ & M. fascicularis & $\begin{array}{c}\text { East and } \\
\text { West Malaysia, Philippines, Thailand }\end{array}$ \\
\hline & $\begin{array}{l}\text { An. pujutensis Colless } \\
\text { (sv)? }\end{array}$ & $\begin{array}{c}\text { Probable vector of } \\
\text { simian malaria } \\
\text { parasites [52] }\end{array}$ & & $\begin{array}{l}\text { Indonesia, East and West Malaysia, } \\
\text { Thailand }\end{array}$ \\
\hline
\end{tabular}

${ }^{1}$ hv,sv and fv indicate human malarial, simian malarial and human lymphatic filarial vectors; sv? Vectorial status awaiting confirmation

Table 1. Simian malaria parasites of Southeast Asia: their Leucosphyrus Group natural vectors, hosts and geographical distribution (modified from Sallum et al [56] 


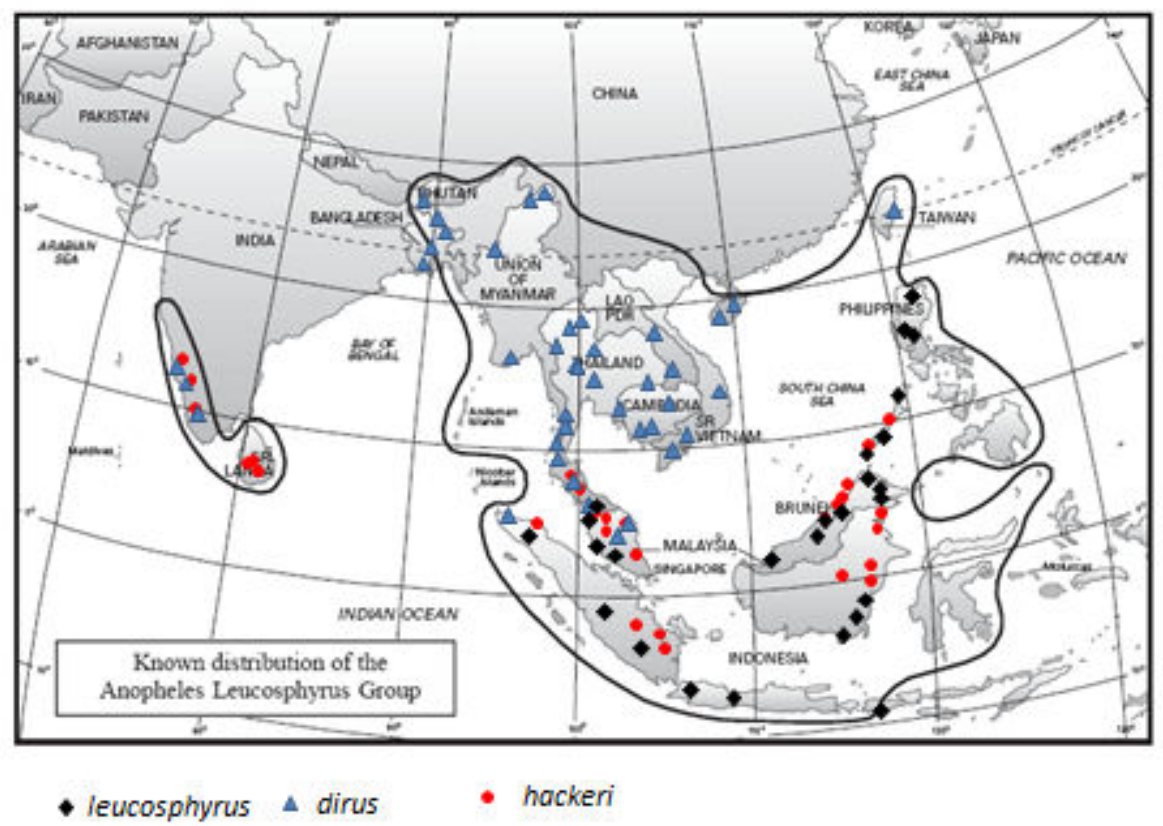

Figure 2. Known limit of the distribution of the An. leucosphyrus Group (An. hackeri Subgroup, An, dirus complex and An. leucosphyrus complex) of mosquitoes in South and Southeast Asia adopted from Sallum et al 2005. Only the distribution of those species mentioned in Table 1 are shown

As a member of the Leucosphyrus complex, An. latens is widely distributed in Borneo (Kalimantan, Sarawak, Sabah) together with An. balabacensis in the forested areas of eastern Borneo (Figure 2). Anopheles latens and An. introlatus are sympatric with members of the closely related Dirus complex in the Malay Peninsula, including southern Thailand [58, 59] (Figure 2).

The Dirus complex is well known because its species are widespread in forest and forest foothills throughout the Oriental Region from southwestern India eastwards and from $30^{\circ}$ north parallel to the Malaysian peninsula [60-62] (Figure2), whereas the Leucosphyrus complex has been investigated to a much lesser degree in Malaysia Borneo and Kalimantan Borneo. Anopheles cracens (Dirus complex) was the predominant mosquito species in a recent study and was never reported previously from Pahang, Malaysia [30]. Earlier reports indicate that An. cracens was found in Perlis (Northern most state of Peninsular, Malaysia) and in Terengganu (east Coast State of Peninsular Malaysia [56]. Its geographic distribution within peninsular Malaysia is unknown [63].

\subsection{Larval biology}

Table 2 shows a summary of Anopheles larval habitat characteristics adapted from Sinka et al [64]. As forest-dwelling species, the immature stages share an affinity for humid, shaded environments where they make use of transient or temporary larval habitats such as pools and pud- 
dles. Like other members of the Leucosphyrus complex, larval habitats of An. lateens and An. balabacensis are mostly shaded temporary pools and natural containers of clear or turbid water on the ground in forest areas (Table 2). Larvae of An. latens are usually found in clear seepage pools in forest swamps in peninsular Malaysia [65] and in pools beside a forest stream and in swampy patches in hilly areas [66]. Habitats occupied by An. latens in Thailand include stump ground holes, sand pools, stream margins, seepage-springs, wheel tracks and elephant foot prints [53,59]. Typical breeding places of An. balabacensis are small pools in clay soil containing fairly clean seepage or rainwater, still or slow moving, and under some shade, with the upper altitudinal limit of $4000 \mathrm{ft}$ in Borneo (1220 meters) [66]. Other adventitious and rare breeding sites include swamp edges or in rock pools, bamboo stumps, split bamboos, tins and other artificial containers [66] and wells in Sandakan, Sabah (unpublished report by Dr David Muir, WHO consultant). In inland forest $A n$. hackeri was found breeding in split bamboo while in the coastal area it was found breeding in the cavities of leaf bases of nipah palm [8].

\begin{tabular}{|c|c|c|c|c|c|}
\hline Species & Light intensity & Turbidity & Water movement & $\begin{array}{l}\text { Small natural } \\
\text { water collections }\end{array}$ & $\begin{array}{l}\text { Small man-made } \\
\text { water collections }\end{array}$ \\
\hline $\begin{array}{l}\text { An. latens \& } \\
\text { leucosphyrus }\end{array}$ & Heliophobic & $\begin{array}{l}\text { Clear, turbid, } \\
\text { fresh water } \\
\text { Muddy pool (W } \\
\text { Malaysia [56]) }\end{array}$ & Still or stagnant & $\begin{array}{c}\text { Small streams, } \\
\text { seepage streams, } \\
\text { pools }\end{array}$ & $\begin{array}{c}\text { Wheel ruts, hoof } \\
\text { prints }\end{array}$ \\
\hline An. balabacensis & Typical heliophobic & Fresh water & Still or stagnant & $\begin{array}{c}\text { Pools; dips in the } \\
\text { ground }\end{array}$ & $\begin{array}{c}\text { Wheel ruts, hoof } \\
\text { prints }\end{array}$ \\
\hline An. dirus & Heliophobic & $\begin{array}{l}\text { Clear, turbid, } \\
\text { fresh water }\end{array}$ & Still or stagnant & $\begin{array}{l}\text { Small streams, } \\
\text { pools, wells, dips } \\
\text { in the ground }\end{array}$ & $\begin{array}{c}\text { Borrow pits, wheel } \\
\text { ruts, hoof prints }\end{array}$ \\
\hline An. hackeri & Heliophobic & $\begin{array}{c}\text { Clean non saline } \\
\text { water, but found } \\
\text { in water } \\
\text { containing up to } \\
4 \% \text { sea-water }\end{array}$ & Still or stagnant & $\begin{array}{c}\text { In split bamboo } \\
\text { and cavities at the } \\
\text { leaf base of nipa } \\
\text { palm }\end{array}$ & $\begin{array}{l}\text { In Thailand, in } \\
\text { elephant } \\
\text { footprints [56] }\end{array}$ \\
\hline
\end{tabular}

Table 2. Larval habitat characteristics of monkey malaria vectors (adapted from Sinka et al [64]) including individual studies reported in the literature.

\subsection{Biological characteristics}

The important biological charactersitics of the known vectors of simian malaria are shown in Table 3 which has been modified from Meek [67]. Of the known vectors, An. hackeri is known to bite only monkeys and rarely comes to bite humans [8]. Although An. latens is a vector of human malaria in East Malaysia [68-70], the current studies have shown that the species is more attracted to monkeys compared to humans [71], whilst An. cracens is attracted to both monkeys and humans [72]. In Palawan Island, Philippines, An. balabacensis was more attracted 
to a monkey bait trap compared to carabao (water buffalo) and human bait traps [73, 74]. It was also found positive for oocysts and sporozoites but could not be confirmed if it was of monkey origin [73]. However, infection studies carried out by the same authors proved that An. balabacensis was the vector of simian malaria in Palawan [73]. So far only the An. Leucosphyrus Group (An. latens, An. cracens, An. balabacensis, An. hackeri and An. dirus) of mosquitoes have been found positive for simian malaria parasites in nature [30, 45, 71, 72, 75-80]. However, An. dirus is also a main vector of both human malaria, with sporozoite rates as high as $14 \%$ in Myanmar and as low as 2.5\% in Lao PDR [61, 81], and Wuchereria bancrofti [82].

\begin{tabular}{|c|c|c|c|c|}
\hline Species & Peak biting time & $\begin{array}{l}\text { Host preference or } \\
\text { MBT:HBT }\end{array}$ & Survivorship & Sporozoite rate/EIR \\
\hline An. latens & $\begin{array}{c}\text { Sarawak: Around } \\
\text { midnight in forested } \\
\text { areas and soon after } \\
\text { dusk in village } \\
\text { settlements [68] } \\
\text { Forest: 1900-2000 h; } \\
\text { farm: 0100-0200 h [69] } \\
\text { Monkey biting rate at } \\
6,3 \text { m above ground } \\
\text { and at ground: } \\
6.8: 3.2: 1.0 \text {. HBR } \\
\text { highest at forest fringe } \\
\text { (6.74\%), within the } \\
\text { forest (1.85\%) and at } \\
\text { long house (0.28\%) } \\
\text { [71] }\end{array}$ & $\begin{array}{l}\text { Similar host preference } \\
1.0: 1.3[71]\end{array}$ & $\begin{array}{l}\text { Sarawak: parous rate } \\
65.8 \% \text { (farm), 53.7\% } \\
\text { (forest), 65.8\% } \\
\text { (longhouse) [71] } \\
\text { VC: } 2.86 \text { (farm), } 0.60 \\
\text { (forest), } 0.85 \\
\text { (longhouse) [71] }\end{array}$ & $\begin{array}{c}\text { Sarawak: } 1.18 \% \\
\text { (pooled from forest } \\
\text { fringe, forest \& } \\
\text { longhouse), } 0.7 \% \\
\text { (farm), } 1.4 \% \text { (forest), al } \\
\text { confirmed Pk by PCR; } \\
\text { EIR } 11.98 \text { (farm), } 14.1 \\
\text { (forest) [71] }\end{array}$ \\
\hline An. balabacensis & $\begin{array}{c}\text { Palawan: In and out; } \\
\text { 20.00-03.00 h [73] } \\
\text { Sabah: 22:00-02:00 h } \\
\text { [85- 86];after midnight } \\
\text { [87] } \\
\text { Out (76\%): } \\
\text { 19:00-20:00 h, } \\
\text { in(24\%): 22:00-23:00 } \\
\text { h;[83] } \\
\text { Lombok: 19:00-21:00h) } \\
\text { [84] }\end{array}$ & $\begin{array}{l}\text { Attracted to humans, } \\
\text { monkey \& water } \\
\text { buffalo; more } \\
\text { frequently caught in } \\
\text { monkey traps [74] }\end{array}$ & $\begin{array}{l}\text { Sabah: highest in Nov, } \\
\text { lowest in July [83] }\end{array}$ & $\begin{array}{c}\text { Kalimantan: } 1.3 \% \text { [88] } \\
\text { Palawan: } 12.5 \% \\
\text { sporozoite rate; } 29 \% \\
\text { attracted to monkeys } \\
\text { were positive for } \\
\text { oocysts [74] }\end{array}$ \\
\hline An. dirus & $\begin{array}{c}\text { Late or early biting, } \\
\text { usually around 22:00 h } \\
{[60-62]}\end{array}$ & Highly anthropophilic, & $\begin{array}{c}\text { Higher parous rate } \\
\text { (76\%) \& life expectancy } \\
\text { during dry season }\end{array}$ & $\begin{array}{l}\text { Human sporozoite } \\
\text { y rates vary with season } \\
\text { and location: from }\end{array}$ \\
\hline
\end{tabular}




\begin{tabular}{|c|c|c|c|c|}
\hline Species & Peak biting time & $\begin{array}{l}\text { Host preference or } \\
\qquad \text { MBT:HBT }\end{array}$ & Survivorship & Sporozoite rate/EIR \\
\hline & $\begin{array}{l}9 \text { of } 13 \text { Plasmodium } \\
\text { positive bites occur } \\
\text { before } 21: 00 \mathrm{~h} \\
\text { (Vietnam) [91] }\end{array}$ & $\begin{array}{c}\text { exophagic as well as } \\
\text { endophagic and } \\
\text { exophilic } \\
\text { [61-62] }\end{array}$ & $\begin{array}{l}\text { compared to wet } \\
\text { season }(62.4 \%) \text { in Lao } \\
\text { [81] }\end{array}$ & $\begin{array}{l}\text { 7.8\% in Assam (India) } \\
\text { to 14\% in Myanmar } \\
\text { [61] and 2.5\% in Laos } \\
\text { [81] } \\
43 \% \text { of } 72 \text { salivary } \\
\text { glands were PCR- } \\
\text { positive for Pk CSP and } \\
\text { Pk 18s rRNA. Mixed } \\
\text { infections of Pk with PV } \\
\text { and Pf were common } \\
\text { in Vietnam [77] }\end{array}$ \\
\hline An. cracens & $\begin{array}{l}\text { Thailand: } 1900-2100 \mathrm{~h} \\
\text { [60] } \\
\text { West Malaysia: } \\
\text { 2000-2100 h; } 74 \% \\
\text { biting before } 2100 \text { h; } \\
\text { predominantly } \\
\text { exophagic ( } 1.11 \text { bites/ } \\
\text { man-night) in both } \\
\text { forest ( } 1.24 \text { bites/man- } \\
\text { night) and fruit orchard } \\
\text { (4.15 bites/man-night); } \\
60 \% \text { biting at ground } \\
\text { level to } 3 \text { m high } \\
\text { before } 00: 00 \text { h; more } \\
\text { biting at canopy level } \\
\text { (6 m) compared to } \\
\text { earlier collections at } \\
\text { the same level [72]. }\end{array}$ & $\begin{array}{l}\text { West Malaysia: 1: } 2.6 \\
\qquad \text { [7.2] }\end{array}$ & $\begin{array}{l}\text { West Malaysia: parous } \\
\text { rate } 65.7 \% \text { (fruit } \\
\text { orchard), } 71.5 \% \\
\text { (forest) } \\
\text { VC: } 2.46 \text { (fruit orchard), } \\
1.09 \text { (forest) [72] }\end{array}$ & $\begin{array}{l}\text { West Malaysia: } 0.60 \% \\
\text { (fruit orchard), } 2.9 \% \\
\text { (forest) } \\
\text { EIR: } 0.08 \text { [72] }\end{array}$ \\
\hline An. hackeri & $\begin{array}{l}\text { Not known since most } \\
\text { bite monkeys and } \\
\text { rarely found in human } \\
\text { bait traps [78] }\end{array}$ & $\begin{array}{l}\text { Most attracted to } \\
\text { monkeys at canopy } \\
\text { level in mangrove } \\
\text { forest does not come } \\
\text { to bite humans [78] }\end{array}$ & No data available & $\begin{array}{c}\text { In coastal area of } \\
\text { Rantau Panjang West } \\
\text { Malaysia } 0.7 \% \\
\text { [78] }\end{array}$ \\
\hline
\end{tabular}

'VC - vectorial capacity; EIR - entomological inoculation rate; PCR - polymerase chain reaction; HBR - human biting rate; MBT- Monkey bait trap; HBT- human bait trap; CSP - circumsporozoite

Table 3. Biological variations among adults of simian malaria vectors in Southeast Asia (modified from Meek 1995 [67]. 
The peak biting times of An. balabacensis vary from place to place as shown in Table 3. It seems to bite as early as 19:00 $\mathrm{h}$ in recent years compared to being late night biters in the previous decades [83-89]. An. dirus s.s. tends to bite between 20:00 and 23:00 $\mathrm{h}[53,56,60]$ and and there is significant biological variability within the Dirus complex, depending on the local circumstances [90]. In Vietnam, sporozoite positive bites from An. dirus occur before 21:00 h [91] and co-infections of $P$. knowlesi, $P$. falciparum and P. vivax $[76,77]$ in mosquitoes are indicative of simultaneous transmission. Plasmodium knowlesi-sporozoite infective An. latens and An. cracens were detected from human landing and monkey bait collections in Sarawak and Pahang, Malaysia, respectively $[71,72]$ suggesting that $P$. knowlesi is being transmitted to both humans and macaques by these two vector species. Generally the parous rates of the Leucosphyrus Group of mosquitoes where relatively high as shown in Table 3. Overall parous rate of An. latens was 59\% and those caught in the forest was significantly lower than those caught at the farm or long house (where native people of Sarawak live) [71], while for An. cracens the parous rate in the forest was higher than in the farm (Table 3), and on average was above $60 \%$ [72]. Heterogeneity in biting rates and parous rates indicates that the vectorial capacities are relatively higher in farms or orchards compared to forests (Table 3), and has significant implications for vector control. Understanding the importance of natural heterogenity in $P$. knowlesi transmission is necessary to elucidate the key variation undermining existing control efforts and to target the vector species for focused interventions [92].

\subsection{Laboratory susceptibility studies}

In laboratory experiments with $P$. knowlesi, An. balabacensis was found to be a successful vector [93]. However, An. maculatus only developed few oocysts and sporozoite infection in salivary glands was of low intensity. Laboratory feeding experiments, An. maculatus was susceptible to $P$. inui and was able to transmit the parasite to the non-human primate host after a prepatent period of 11 days [94]. In a series of experiments infectivity conducted in the Institute for Medical Research, with the Gombak strain of P. cynomolgi, the following mosquitoes were found with salivary gland infections: An. maculatus, An. kochi, An. sundaicus (=An. epiroticus), $A n$. vagus and An. introlatus [16]. However, in field situation it was observed that An. maculatus was not attracted to macaques, with only three female mosquitoes entering the monkey bait trap [72]. While An. kochi was the second predominant mosquito entering monkey baited trap, none were positive for oocyst or sporozoites [72]. Thus, although species other than the Leucosphyrus Group were able to develop the simian malaria parasites to sporozoites, none were incriminated in nature except the Leucosphyrus Group.

\subsection{Trapping techniques}

Various trapping methods were tested for the collection of Anopheles mosquitoes attracted to non-human primates. Earlier observations indicated that these mosquitoes prefer to feed well above ground level and especially about 6-8 $\mathrm{m}$ above ground level. Thus, platforms were built among foliage in the forest or plantations to house the non-human primates for mosquito collections. The following traps that were tested [95] are described hereunder. 


\section{Net Traps}

This is similar to the human-bait-net trap introduced by Gater [96]. This method provided the best results when tested [95]. The platforms were constructed among the branches of trees to a height of 6 meters. Special metal cages measuring $90 \mathrm{~cm} \times 90 \mathrm{~cm} \times 90 \mathrm{~cm}$ and covered by wire mesh were used to house the monkeys on the platform measuring $300 \mathrm{~cm}$ X $200 \mathrm{~cm}$. The meshed cages provided a physical barrier to prevent the monkeys from grabbing the collectors and also to prevent the entry of snakes. It is ideal to have two monkeys sharing a cage to increase vector attraction. A mosquito net measuring $190 \mathrm{~cm} \times 180 \mathrm{~cm} \times 150 \mathrm{~cm}$ with an opening of about $40 \mathrm{~cm}$ lifted on either ends was used to cover the cages with monkeys on each platform. The traps were operated from 18:00 to 06:00 hours and were searched at regular intervals [71, 72]. A collector, upon entering the net, closed the openings and collected all resting mosquitoes with the use of aspirators. Mosquitoes in the aspirator were then transferred to paper cups and were brought to the laboratory for identification and dissection. Platforms were built at various heights, ground level, 3 and 6 meters above ground. Figure 3 shows two different platforms in operation.
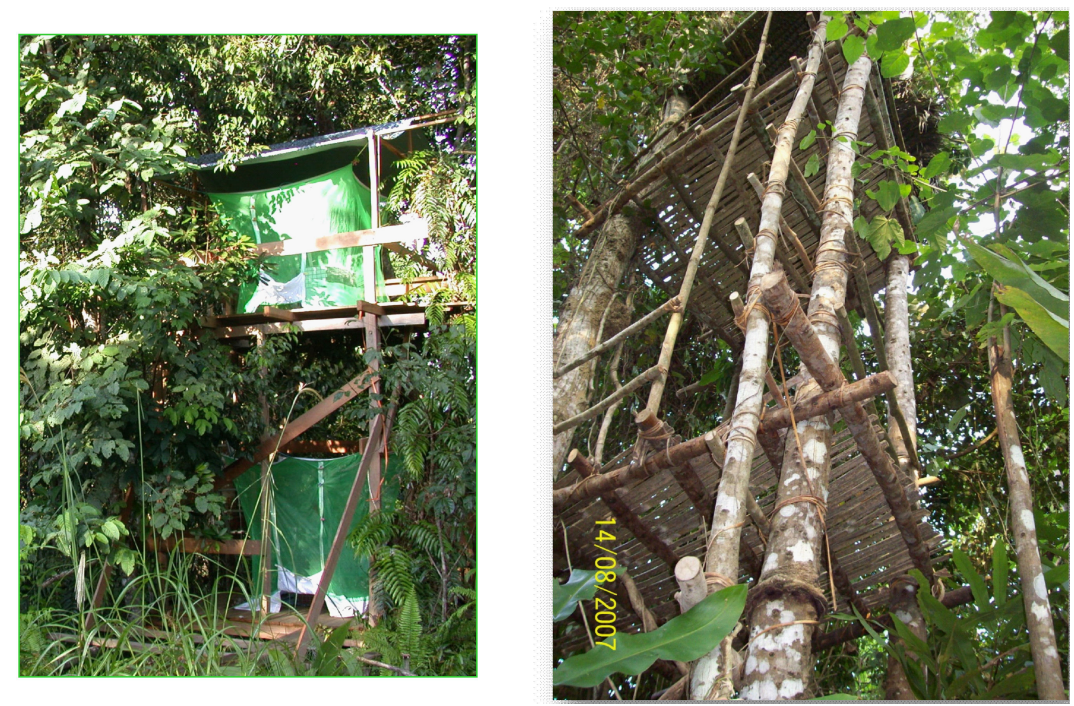

Figure 3. Monkey Baited Net Traps at different levels on platform.

The other traps used were Shannon net trap, drum funnel-trap, Lumsden suction trap and light traps. Detailed descriptions can be found in Wharton [95]. Of all the traps tested, it was found that the monkey- baited traps were superior compared to other types of traps. Although it is a difficult task to collect mosquitoes from the platforms at regular intervals, it is no doubt important to study the behaviour of the mosquitoes. Studies by Wharton [95] demonstrated that $83 \%$ of the An. hackeri were collected in catches made before midnight, compared to only $62 \%$ and $65.8 \%$ of $A n$. latens and An. cracens caught before midnight respectively [71, 72]. Thus, 
it seems that all night collection is still important despite logistical difficulties, costliness, tediousness and human fatigue.

\section{Implications for control}

Currently insecticide treated bednets (ITN) and indoor residual spraying (IRS) are the two most important tools for the control of malaria vectors. Scaling up ITN, IRS, artemisinin-based combination therapies and intermittent preventive treatment for infants and pregnant women have contributed to the reported reductions in malaria on a global scale [97]. As part of the Global Malaria Action Plan, the RBM Partnership and World Health Organization has recommended "malaria eradication worldwide by reducing the global incidence to zero through progressive malaria elimination in countries" [98]. However, if human malaria could be eliminated, forests in Southeast Asia provide favourable environments for zoonotic transmission of $P$. knowlesi thus, thwarting efforts to eliminate malaria.

The vectors of $P$. knowlesi malaria have been incriminated only from certain districts or locations in Malaysia [71, 72, 75]. Given that the vectors of monkey malaria show anthropophagic, exophagic and exophilic tendencies, it is obvious that the existing front-line vector control tools (IRS, ITN) will not be sufficient to reduce vector density and break the transmission cycle of $P$. knowlesi in the most intensively endemic parts of Southeast Asia. Innovative interventions are needed to control simio-anthropophagic and acrodendrophilic vectors that do not rest and feed indoors. There are two major problems that need to be addressed before considering malaria elimination. It is known that $P$. knowlesi can be life threatening [99] and mortality due to it is increasing [31, 100]. Thus it is important to determine the vectors throughout the country; study the behavior and ecology of the species of mosquitoes and apply the most effective strategy(ies) for control of these vector. To achieve these outcomes, several key areas for strategic investment relevant for malaria elimination have been proposed [101]. Second, there will always be a problem of human population movement (HPM) and thus people moving into the jungle may introduce the parasite which could give rise to new infections if suitable vectors are present and readily establish local transmission. HPM is common among migrants in the Greater Mekong Subregion [102] and in Southeast Asia [103].

In Vietnam, forest malaria caused by An. dirus was controlled because workers going into the forest used long lasting insecticide hammocks (LLIH) [104]. The use of LLIH can be encouraged in ecotourism areas where people stay overnight in the community managed guest houses or camps in the forest. However, other types of personal protection methods need to be evaluated for forest workers. A study has demonstrated that military personnel who used permethrin treated uniforms were protected against mosquito bites, thereby reducing malaria transmission [105].

The use of repellents as personal protection measures have been advocated for malaria control. However, this needs to be evaluated in forest settings and large scale implementation will be a public health challenge. Among US Military troops, malaria cases have been reported due to non-compliance of personal protective measures and failure of chemoprophylaxis [106]. 
Currently in Malaysia people are getting infected when they visit plantations or forests for work or recreational activities as some important vectors do not enter houses [72].

\section{Challenges}

There is no reason to doubt the possibility and biological capacity of other simian malaria species to infect humans $[13,107]$. An. latens can develop all the five species of simian malaria [79] and has a biting preference for both humans and macaques, the possibility of humans being infected with $P$. cynomologi or $P$. inui needs to be addressed. As stated by Baird [108], in areas where macaques and vectors are in close proximity to humans and when malaria occurs other species should also be considered and not just the human malarias and P. knowlesi.

Currently only three species of mosquitoes have been incriminated as simian malaria vectors in Malaysia (An. balabacensis, An. cracens and An. latens) $[45,71,72,75]$ and one in Vietnam (An. dirus) $[76,77]$. However, it is beyond doubt that there would be several more species involved that would feed on both humans and monkeys and establish natural transmission. Before the inception of the malaria eradication program there were many more Anopheles species that were vectors [109], but some species were successfully brought down to very low levels due to their endophilic/endophagic behaviours and susceptibility to residual insecticides. Thus the aggressive national control programme has resulted controlling in only three to four important vectors occurring in Malaysia (An. balabacensis, An. flavirostris, An. latens, An. maculatus), [110-113].

In Thailand, the main vectors for human malaria are An. dirus, An. minimus and An. maculatus, mosquitoes [114]. Although An. dirus mosquitoes which belong to the Leucosphyrus Group and have been identified as potential vectors for P. knowlesi in Vietnam [76, 77], its distribution and abundance have significantly decreased in all major malaria-endemic areas of Thailand during the past decade [34]. Human cases of $P$. knowlesi have been reported from Thailand at a low prevalence $(0.57 \%$ in $2006-2007)$, however the vector remains unknown [34].

According to Obsomer et al [61] the mean temperature below $20^{\circ} \mathrm{C}$ seems to limit the northern distribution of the Dirus complex to just beyond the border of India with Nepal and Bhutan. Rainfall is probably the limiting factor to the west with annual rainfall per year under $800 \mathrm{~mm}$. Thus the lack of information on the distribution and occurrence of $P$. knowlesi cases in large non-forested areas of Thailand, southern Vietnam and central India is probably linked with the lack of suitable habitats [61]. The absence of the complex (besides the newly described species aff. takasagoensis) in north of Vietnam is puzzling as this area is still forested and members of the complex occur at the same latitude in neighbouring countries. Laos PDR is the only country in the Greater Mekong Subregion that has not reported the occurrence of $P$. knowlesi malaria. This may be due to the fact that so far investigations have not been carried out for P. knowlesi.

Thus it is timely to determine all the vectors of simian malaria throughout the Southeast Asian region. Although old records stating the distribution of the various Anopheles species are 
available, it may not depict the current situation since landscape ecology and vegetation cover have significantly changed over time. The distribution of vectors, in relation to forest areas and human settlements using modern technology such as the GPS, GIS and the behavioral ecology of the vectors, needs to be addressed. These and other key areas identified for specific strategic investment in ecological research [101] should assist to define the target product profiles of completely new control technologies and delivery systems.

\section{Conclusion}

Since many malaria control programmes in Southeast Asia are moving towards elimination of malaria [115], it is important to determine the prevalence of knowlesi malaria in these countries. In the Greater Mekong Subregion including Bangladesh and India An. dirus is one of the primary vector of human malaria and thus it is important to determine if other vectors are involved in knowlesi transmission. Among habitats shared by macaques and vector mosquitoes, it is possible for humans who encroach these areas to be infected. Thus, important issues that need to be determined are as follows: Are other simian malaria parasites affecting humans? Is human to human transmission occurring? What are the other vectors transmitting simian malaria to humans (apart from An. cracens, An. latens, An.dirus and An. balabacensis) in the region and what roles do they play in host switching? What innovative technologies or biting prevention are appropriate for the control of these vectors? Thus, knowlesi malaria remains a great challenge for the future.

\section{Acknowledgements}

The authors thank Pollie Rueda for his constructive comments. The first author was supported by a grant from University of Malaya UM.C/625/1/HIR/099.J-20011-73822

\section{Author details}

Indra Vythilingam ${ }^{1,3^{*}}$ and Jeffery $\mathrm{Hii}^{2,3}$

*Address all correspondence to: indra.vythilingam@gmail.com

1 Parasitology Department, Faculty of Medicine, University of Malaya, Kuala Lumpur, Malaysia

2 Taman Damai, Jalan Fung Yei Ting, Kota Kinabalu, Sabah, Malaysia

3 Formerly WHO Malaria Scientist, World Health Organization, Philippines 


\section{References}

[1] Daniels CW. Animal parasites in man and some of the lower animals in Malaya. Studies Institite for Medical Research FMS 1908;3:1-13.

[2] Coatney GR. Simian malaria: Its importance to world wide eradication of malaria. Journal of American Medical Association 1963;184:876-7.

[3] Contacos PG, Elder HA, Coatney GR. Man to man transfer of two strains of Plasmodium cynomolgi by mosquito bites. American Journal of Tropical Medicine and Hygiene 1962;11:186-93.

[4] Chin W, Contacos PG, Coatney GR, Kimball HR. A naturally acquired quotidiantype malaria in man transferable to monkeys. Science 1965;149:865.

[5] Sinton JA MH. A critical review of the literature relating to the identification of the malaria parasites recorded from monkeys of the families Cercopithecidae and Colobidae. Rec Malaria Surv India 1932-1933;III:357-443.

[6] Warren MW, Cheong WH, Fredericks HK, Coatney GR. Cycles of jungle malaria in West Malaysia. American Journal of Tropical Medicine and Hygiene 1970;19:383.

[7] Fong YL, Cadigan FC, Coatney GR. A presumptive case of naturally occurring Plasmodium knowlesi malaria in man in Malaysia. Transactions of Royal Society of Tropical Medicine and Hygiene 1971;65:839.

[8] Wharton RH, Eyles DE. Anopheles hackeri, a vector of Plasmodium knowlesi in Malaya. Science 1961;134:279.

[9] Chin W, Contacos PG, Collins WE, Jeter MH, Alpert E. Experimental mosquito-transmission of Plasmodium knowlesi to man and monkey. American Journal of Tropical Medicine and Hygiene 1968;17:355-8.

[10] Singh B, Sung LK, Matusop A, Radhakrishnan A, Shamsul SSG, Cox-Singh J, et al. A large focus of naturally acquired Plasmodium knowlesi infections in human beings. Lancet 2004;363:1017-24.

[11] Collins WE. Major animal models in malaria research: Simian. In: Wernsdofer WH and McGregor editors. Malaria: Principles and Practice of Malariology. Edinburgh: Churchill Livingstone; 1988. p. 1473-501.

[12] Fodden J. Malaria in Macaques. International Journal of Primatology 1994;15:573-96.

[13] Galinski MR, Barnwell JW. Monkey malaria kills four humans. Trends in Parasitology 2009;25:200-4.

[14] Lee KS, Divis PCS, Zakaria SK, Matusop A, Julin RA, Conway DJ, et al. Plasmodium knowlesi: reservoir hosts and tracking the emergence in humans and macaques. PLoS Pathogens 2011;7:e1002015. 
[15] Coatney GR, Elder HA, Contacos PG, Getz ME, Greenland R, Rossan RN, et al. Transmission of the $\mathrm{M}$ strain of Plasmodium cynomolgi to man. The American Journal of Tropical Medicine and Hygiene 1961;10:673-8.

[16] Collins WE, Warren MW, Sullivan JAS, Galland GG, Nace D, Williams A, et al. Studies on two strains of Plasmodium cynomolgi in New World and Old World monkeys and mosquitoes. Journal of Parasitology 2005;91:280-3.

[17] Eyles DE, Laing ABG, Fong YL. Plasmodium fieldi sp nov, a new species of malaria parasite from the pig-tailed macaque in Malaya. Annals of Tropical Medicine and Parasitology 1962;56:242-7.

[18] Eyles DE. The species of simian malaria: Taxonomy, morphology, life cycle, and geographical distribution of the monkey species. Journal of Parasitology 1963:866-87.

[19] Eyles DE, Laing ABG, Dobrovolny CG. The malaria parasites of the pig-tailed macaque, Macaca nemestrina (Linnaeus). Indian Journal of Malariology 1962;16:285-98.

[20] Eyles DE, Laing ABG, Warren M, Sandosham AA. Malaria parasites of the Malayan leaf monkeys of the genus Presbytis. Medical Journal of Malay 1962;17:85-6.

[21] Li M. Identification and molecular characterization of simian malaria parasites in wild monkeys of Singapore. Singapore: National University of Singapore; 2011.

[22] Ho G, Lee C, Abie M, Zainuddin Z, Japnin J, Topani R, et al. Prevalance of Plasmodium in the Long-tailored Macaque (Macaca fasicularis) from Selangor, Malaysia. Proceedings 13th Association of Institutions for Tropical Veterinary Medicine (AITVM) Conference 2010:49.

[23] Eyles DE, Fong, Y.1.,Warren, Mc,W., Guinn,E.,Sabdosham,AA.,Wharton,R.H. Plasmodium coatneyi, a new species of primate malaria from Malaya. American Journal of Tropical Medicine and Hygiene 1962;11:597-604.

[24] Eyles DE, Dunn F, Warren McW, Guinn E. Plasmodium coatneyi from the Philippines. Journal of Parasitology 1963;49:1038.

[25] Sandosham A. Recent researchers on malaria at the Institute for Medical Research, Kuala Lumpur. Medical Journal of Malaysia 1967;22:145-60.

[26] Lee KS, Cox-Singh J, Singh B. Morphological features and differential counts of Plasmodium knowlesi parasites in naturally acquired human infections. Malaria Journal 2009;8:73.

[27] Coatney RG, Collins WE, Warren M, Contacos PG. The Primate Malarias. Washington: U.S. Government Printing Office; 1971.

[28] Sandosham AA. Malariology with special reference to Malaya Singapore. Kuala Lumpur: University of Malaya Press; 1959. 
[29] Cox Singh J, Davis TME, Lee KS, Shamsul SSG, Matusop A, Ratnam S, et al. Plasmodium knowlesi malaria in humans is widely distributed and potentially life threatening. Clinical Infectious Diseases 2008;46:165-71.

[30] Vythilingam I, NoorAzian YM, Huat TC, Jiram AI, Yusri YM, Azahari AH, et al. Plasmodium knowlesi in humans, macaques and mosquitoes in peninsular Malaysia. Parasite Vectors 2008;1:26.

[31] William T, Menon J, Rajahram G, Chan L, Ma G, Donaldson S, et al. Severe Plasmodium knowlesi malaria in a tertiary care hospital, Sabah, Malaysia. Emerging Infectious Diseases 2011;17:1248-54.

[32] Barber BE, William T, Jikal M, Jilip J, Dhararaj P, Menon J, et al. Plasmodium knowlesi malaria in children. Emerging Infectious Diseases 2011;17:20.

[33] Jongwutiwes S, Putaporntip C, Iwasaki T, Sata T, Kanbara H. Naturally acquired Plasmodium knowlesi malaria in human, Thailand. Emerging Infectious Diseases 2004;10:2211-3.

[34] Jongwutiwes S, Buppan P, Kosuvin R, Seethamchai S, Pattanawong U, Sirichaisinthop J, et al. Plasmodium knowlesi Malaria in humans and macaques, Thailand. Emerging Infectious Diseases 2011;17:1799-806.

[35] Putaporntip C, Hongsrimuang T, Seethamchai S, Kobasa T, Limkittikul K, Cui L, et al. Differential prevalence of Plasmodium infections and cryptic Plasmodium knowlesi malaria in humans in Thailand. Journal of Infectious Diseases 2009;199:1143.

[36] Luchavez J, Espino F, Curameng P, Espina R, Bell D, Chiodini P, et al. Human infections with Plasmodium knowlesi, the Philippines. Emerging Infectious Diseases 2008;14:811-3.

[37] Eede P, Van H, Van Overmeir C, Vythilingam I, Duc T, Hung L, et al. Human Plasmodium knowlesi infections in young children in central Vietnam. Malaria Journal 2009;8:249.

[38] Sulistyaningsih E, Fitri LE, Löscher T, Berens-Riha N. Diagnostic difficulties with Plasmodium knowlesi infection in humans. Emerging Infectious Diseases 2010;16:1033.

[39] Khim N, Siv S, Kim S, Mueller T, Fleischmann E, Singh B, et al. Plasmodium knowlesi infection in humans, Cambodia, 2007-2010. Emerging Infectious Diseases 2011;17:1900.

[40] Zhu H, Li J, Zheng H. Human natural infection of Plasmodium knowlesi. Zhongguo ji sheng chong xue yu ji sheng chong bing za zhi= Chinese Journal Parasitology Parasite Diseases 2006;24:70.

[41] Ng OT, Ooi EE, Lee CC, Lee PJ, Ng LC, Pei SW, et al. Naturally acquired human Plasmodium knowlesi infection, Singapore. Emerging Infectious Diseases 2008;14:814. 
[42] White N. Plasmodium knowlesi: the fifth human malaria parasite. Clinical Infectious Diseases 2008;46:172.

[43] Anderios F, NoorRain A, Vythilingam I. In vivo study of human Plasmodium knowlesi in Macaca fascicularis. Experimental Parasitology 2010;124:181-9.

[44] Garnham P. Malaria parasites and other haemosporidia. Oxford: Blackwell Scientific Publications; 1966.

[45] Vythilingam I. Review Paper Plasmodium knowlesi in humans: a review on the role of its vectors in Malaysia. Tropical Biomedicine 2010;27:1-12.

[46] Hoosen A, Shaw M. Plasmodium knowlesi in a traveller returning to New Zealand. Travel Medicine and Infectious Disease 2011;9:144-8.

[47] Mali S, Steele S, Slutsker L, Arguin PM. Malaria surveillance-United states, 2006. MMWR Surveill Summ 2008;57:24-39.

[48] Kantele A, Marti H, Felger I, Muller D, Jokiranta TS. Monkey Malaria in a European Traveler Returning from Malaysia. Emerging Infectious Diseases 2008;14:1434-6.

[49] Bronner U, Divis PCS, Farnert A, Singh B. Swedish traveller with Plasmodium knowlesi malaria after visiting Malaysian Borneo: a case report. Malaria Journal 2009;8:15.

[50] Tang TH, Salas A, Ali-Tammam M, Martínez M, Lanza M, Arroyo E, et al. First case of detection of Plasmodium knowlesi in Spain by Real Time PCR in a traveller from Southeast Asia. Malaria Journal 2010;9:219.

[51] Berry A, Iriart X, Wilhelm N, Valentin A, Cassaing S, Witkowski B, et al. Imported Plasmodium knowlesi malaria in a French tourist returning from Thailand. American Journal of Tropical Medicine and Hygiene 2011;84:535-8.

[52] Warren MW, Wharton RH. The vectors of simian malaria: identity, biology, and geographical distribution. Journal of Parasitology 1963:892-904.

[53] Sallum MAM, Peyton EL, Wilkerson RC. Six new species of the Anopheles leucosphyrus group, reinterpretation of An. elegans and vector implications. Medical and Veterinary Entomology 2005;19:158-99.

[54] Harbach RE. The classification of genus Anopheles (Diptera: Culicidae): a working hypothesis of phylogenetic relationships. Bulletin of Entomological Research 2004;94:537-54.

[55] Peyton E. A new classification for the Leucosphyrus Group of Anopheles (Cellia). Mosquito Systematics 1989;21:197-205.

[56] Sallum MAM, Peyton EL, Harrison BA, Wilkerson RC. Revision of the Leucosphyrus group of Anopheles (Cellia)(Diptera, Culicidae). Revista Brasileira de Entomolo 2005;49:01-152.

[57] Manguin S, Garros C, Dusfour I, Harbach RE, Coosemans M. Bionomics, taxonomy, and distribution of the major malaria vector taxa of Anopheles subgenus Cellia in 
Southeast Asia: An updated review. Infection, Genetics and Evolution 2008;8:489-503.

[58] Rattanarithikul R, Harrison BA. An illustrated key to the Anopheles larvae of Thailand. United State Army Medical Component, South East Asia Treaty Organization, Bangkok 1973.

[59] Rattanarithikul R, Harrison BA, Harbach RE, Panthusiri P, Coleman RE. Illustrated keys to the mosquitoes of Thailand. IV. Anopheles. Southeast Asian Journal of Tropical Medicine Public Health 2006;37 1-128.

[60] Baimai V, Kijchalao U, Sawadwongporn P, Green CA. Geographic distribution and biting behaviour of four species of the Anopheles dirus complex (Diptera: Culicidae) in Thailand. Southeast Asian Journal of Tropical Medicine Public Health 1988;19:151-61.

[61] Obsomer V, Defourny P, Coosemans M. The Anopheles dirus complex: spatial distribution and environmental drivers. Malaria Journal 2007;6:26.

[62] Trung HD, Bortel WV, Sochantha T, Keokenchanh K, Briët OJT, Coosemans M. Behavioural heterogeneity of Anopheles species in ecologically different localities in Southeast Asia: a challenge for vector control. Tropical Medicine \& International Health 2005;10:251-62.

[63] Vythilingam I. Plasmodium knowlesi and Wuchereria bancrofti: their vectors and challenges for the future. Frontiers in Systems Biology 2012;3.

[64] Sinka ME, Bangs MJ, Manguin S, Chareonviriyaphap T, Patil AP, Temperley WH, et al. The dominant Anopheles vectors of human malaria in the Asia-Pacific region: occurrence data, distribution maps and bionomic précis. Parasite Vectors 2011;4:1-46.

[65] Reid JA. Anopheline Mosquitoes of Malaya and Borneo. Malaysia: Institute for Medical Research Malaysia; 1968.

[66] Colless D. The Anopheles leucosphyrus group. Transactions of Royal Entomological Society London 1956;108:37-116.

[67] Meek S. Vector control in some countries of Southeast Asia: comparing the vectors and the strategies. Annals of Tropical Medicine and Parasitology 1995;89:135-47.

[68] Chang MS, Doraisingam P, Hardin S, Nagum N. Malaria and filariasis transmission in a village/forest setting in Baram District, Sarawak, Malaysia. Journal of Tropical Medicine and Hygiene 1995;98:192.

[69] Colless DH. Observations on Anopheline mosquitoes of the Akah river, 4th Division, Sarawak. Bulletin of Entomological Research 1956;47:115-23.

[70] Zulueta J. Malaria in Sarawak. Bulletin World Health Organisation 1956;15:651-71. 
[71] Tan CH, Vythilingam I, Matusop A, Chan ST, Singh B. Bionomics of Anopheles latens in Kapit, Sarawak, Malaysian Borneo in relation to the transmission of zoonotic simian malaria parasite Plasmodium knowlesi. Malaria Journal 2008;7:52.

[72] Jiram AI, Vythilingam I, NoorAzian YM, Yusof YM, Azahari AH, Fong MY. Entomologic investigation of Plasmodium knowlesi vectors in Kuala Lipis, Pahang, Malaysia. Malaria Journal 2012;11:213.

[73] Tsukamoto M, Miyata A, Miyagi I. Surveys on simian malaria parasites and their vector in Palawan Island, the Philippines. Tropical Medicine 1978;20:39-50.

[74] Miyagi I. Studies on malaria vectors in Philippines especially on Anopheles balabacensis balabacensis and monkey malaria in Palawan. The Journal of Tropical Medicine 1973;2:163.

[75] Vythilingam I, Tan CH, Asmad M, Chan ST, Lee KS, Singh B. Natural transmission of Plasmodium knowlesi to humans by Anopheles latens in Sarawak, Malaysia. Transactions Royal Society Tropical Medicine Hygiene 2006;100:1087-8.

[76] Nakazawa S, Marchand RP, Quang NT, Culleton R, Manh ND, Maeno Y. Anopheles dirus co-infection with human and monkey malaria parasites in Vietnam. International Journal of Parasitology 2009;39:1533-7.

[77] Marchand RP, Culleton R, Maeno Y, Quang NT, Nakazawa S. Co-infections of Plasmodium knowlesi, P. falciparum, and P. vivax among humans and Anopheles dirus mosquitoes, southern Vietnam. Emerging Infectious Diseases 2011;17:1232-9.

[78] Wharton RH, Eyles DE, Warren M, Cheong WH. Studies to determine the vectors of monkey malaria in Malaya. Annals of Tropical Medicine and Parasitology 1964;58:56.

[79] Tan CH. Identification of vectors of Plasmodium knowlesi and other malaria parasites, and studies on their bionomics in Kapit, Sarawak, Malaysia. MSc Thesis University Malaysia, Sarawak (UNIMAS) 2008.

[80] Cheong WH, Warren MW, Omar AH, Mahadevan S. Anopheles balabacensis balabacensis identified as vector of simian malaria in Malaysia. Science 1965;150:1314.

[81] Vythilingam I, Phetsouvanh R, Keokenchanh K, Yengmala V, Vanisaveth V, Phompida $S$, et al. The prevalence of Anopheles (Diptera: Culicidae) mosquitoes in Sekong Province, Lao PDR in relation to malaria transmission. Tropical Medicine International Health 2003;8:525-35.

[82] Pothikasikorn J, Bangs MJ, Boonplueang R, Chareonviriyaphap T. Susceptibility of various mosquitoes of Thailand to nocturnal subperiodic Wuchereria bancrofti. Journal of Vector Ecology 2008;33:313-20.

[83] Vythilingam I, Chan ST, Shanmugratnam C, Tanrang H, Chooi KH. The impact of development and malaria control activities on its vectors in the Kinabatangan area of Sabah, East Malaysia. Acta Tropica 2005;96:24-30. 
[84] Maekawa Y, Tsuda Y, Dachlan YP, Yotopranoto S, Gerudug IK, Yoshinaga K, et al. Anopheline fauna and incriminatory malaria vectors in malaria endemic areas on Lombok Island, Indonesia. Medical Entomology and Zoology 2009;60:1-11.

[85] Hii J. Evidence for the existence of genetic variability in the tendency of Anopheles balabacensis to rest in houses and to bite man. The Southeast Asian Journal of Tropical Medicine and Public Health 1985;16:173.

[86] Rohani A, Lokman Hakim S, Hassan AR, Chan ST, Ong YF, Abdullah AG, Lee HL Bionomics of Anopheles balabacensis Baisas, the Principal Malaria Vector in Ranau, Sabah. Tropical Biomedicine 1999;16:31-8.

[87] Chiang G, Cheong W, Samarawickrema W, Mak J, Kan S. Filariasis in Bengkoka Peninsula, Sabah, Malaysia: vector studies in relation to the transmission of filariasis. The Southeast Asian Journal of Tropical Medicine and Public Health 1984;15:179.

[88] Schultz G. Biting activity of mosquitoes (Diptera: Culicidae) at a malarious site in Palawan, Republic of The Philippines. Southeast Asian Journal Tropical Medicine and Public Health 1992;23:464-9.

[89] Harbach RE, Baimai V, Sukowati S. Some observations on sympatric populations of the malaria vectors Anopheles leucoshpyrus and Anopheles balabacensis in a village forest setting in South Kalimantan. Southeast Asian Journal of Tropical Medicine and Public Health 1987;18:241-7.

[90] Sungvornyothin S, Kongmee M, Muenvorn V, Polsomboon S, Bangs MJ, Prabaripai A, et al. Seasonal abundance and bloodfeeding activity of Anopheles dirus sensu lato in western Thailand. Journal of the American Mosquito Control Association 2009;25:425-30.

[91] Van Bortel W, Trung HD, Hoi le X, Van Ham N, Van Chut N, Luu ND, Roelants P, et al. Malaria transmission and vector behaviour in a forested malaria focus in central Vietnam and the implications for vector control. Malaria Journal 2010;9:373.

[92] Lambrechts L, Knox TB, Wong J, Liebman KA, Albright RG, Stoddard ST. Shifting priorities in vector biology to improve control of vector borne disease. Tropical Medicine \& International Health 2009;14:1505-14.

[93] Collins WE, Contacos PG, Guinn EG. Studies on the transmission of simian malarias II. Transmission of the H strain of Plasmodium knowlesi by Anopheles balabacensis balabacensis. Journal of Parasitology 1967:841-4.

[94] Collins WE, Contacos PG, Guinn EG, Held JR. Studies on the transmission of simian malarias, I. Transmission of two strains of Plasmodium inui by Anopheles maculatus and A. stephensi. Journal of Parasitology 1966:664-8.

[95] Wharton RH, Eyles DE, Warren McW. The development of methods for trapping the vectors of monkey malaria. Annals of Tropical Medicine and Parasitology 1963;57:32-46. 
[96] Gater BAR. Aids to the identification of anopheline imagines in Malaya. Singapore: Government Printer; 1935.

[97] Takken W, Knols BGJ. Malaria vector control: current and future strategies. Trends in Parasitology 2009;25:101-4.

[98] WHO. The global malaria action plan for a malaria free world. http://wwwrollbackmalariaorg/gmap accessed 18Sept 2012. Geneva 2008.

[99] Cox-Singh J, Singh B. Knowlesi malaria: newly emergent and of public health importance? Trends in Parasitology 2008;24:406-10.

[100] Rajahram GS, Barber BE, William T, Menon J, Anstey NM, Yeo TW. Deaths due to Plasmodium knowlesi malaria in Sabah, Malaysia: association with reporting as Plasmodium malariae and delayed parenteral artesunate. Malaria Journal 2012;11:284.

[101] Ferguson HM DA, Beeche A, Borgemeister C, Gottlieb M, et al. Ecology: A Prerequisite for Malaria Elimination and Eradication. PLoS Medicine 2012;7(8):e1000303. doi: 10.1371/journal.pmed.

[102] Delacollette C, D'Souza C, Christophel E, Thimasarn K, Abdur R, Bell D, et al. Malaria trends and challenges in the Greater Mekong Subregion. Southeast Asian Journal of Tropical Medicine and Public Health 2009;40:674.

[103] Organisation Internationale pour les Migration. Situation report on international migration in East and Southeast Asia. 2008.

[104] Thang ND, Erhart A, Speybroeck N, Xa NX, Thanh NN, Van Ky P, et al. Long-lasting insecticidal hammocks for controlling forest malaria: a community-based trial in a rural area of central Vietnam. PloS One 2009;4:e7369.

[105] Deparis X, Frere B, Lamizana M, N'Guessan R, Leroux F, Lefevre P, et al. Efficacy of permethrin-treated uniforms in combination with DEET topical repellent for protection of French military troops in Cote d'Ivoire. Journal of Medical Entomology 2004;41:914-21.

[106] Wallace MR, Sharp TW, Smoak B, Iriye C, Rozmajzl P, Thornton SA, et al. Malaria among United States troops in Somalia. The American Journal of Medicine 1996;100:49-55.

[107] Collins WE. Plasmodium knowlesi: A Malaria Parasite of Monkeys and Humans. Annual Review of Entomology 2012;57.

[108] Baird JK. Malaria zoonoses. Travel Med and Infect Dis 2009;7:269-77.

[109] Sandosham AA, Thomas V. Malariology: with special reference to Malaya: Coronet Books; 1983.

[110] Rahman WA, Che'Rus A, Ahmad AH. Malaria and Anopheles mosquitos in Malaysia. Southeast Asian Journal of Tropical Medicine and Public Health 1997;28:599. 
[111] Vythilingam I, Foo LC, Chiang GL, Chan ST, Eng KL, Mahadevan S, et al. The impact of permethrin impregnated bednets on the malaria vector Anopheles maculatus (Diptera: Culicidae) in aboriginal villages of Pos Betau Pahang, Malaysia. Southeast Asian Journal of Tropical Medicine and Public Health 1995;26:354-8.

[112] Chang MS, Hii J, Buttner P, Mansoor F. Changes in abundance and behaviour of vector mosquitoes induced by land use during the development of an oil palm plantation in Sarawak. Trans Roy Soc Trop Med Hyg 1997;91:382-6.

[113] Hii JLK, Kan S, Vun YS, Chin KF, Lye MS, Mak JW, et al. Anopheles flavirostris incriminated as a vector of malaria and Bancroftian filariasis in Banggi Island, Sabah, Malaysia. Transactions of the Royal Society of Tropical Medicine and Hygiene 1985;79:677-80.

[114] Chareonviriyaphap T, Bangs MJ, Ratanatham S. Status of malaria in Thailand. Southeast Asian Journal of Tropical Medicine and Public Health 2000;31:225-37.

[115] APMEN. Vietnam joins Asia Pacific Malaria Elimination Network (APMEN). http:// apmenorg/storage/newsmedia/Vietnam assessed 18 Sept 2012. 